\title{
Existence and Uniqueness of Solutions for BVP of Nonlinear Fractional Differential Equation
}

\author{
Cheng-Min Su, Jian-Ping Sun, and Ya-Hong Zhao \\ Department of Applied Mathematics, Lanzhou University of Technology, Lanzhou 730050, China \\ Correspondence should be addressed to Jian-Ping Sun; jpsun@lut.cn
}

Received 11 October 2016; Revised 14 December 2016; Accepted 15 December 2016; Published 29 January 2017

Academic Editor: Julio D. Rossi

Copyright (c) 2017 Cheng-Min Su et al. This is an open access article distributed under the Creative Commons Attribution License, which permits unrestricted use, distribution, and reproduction in any medium, provided the original work is properly cited.

\begin{abstract}
In this paper, we study the existence and uniqueness of solutions for the following boundary value problem of nonlinear fractional differential equation: $\left({ }^{C} D_{0+}^{q} u\right)(t)=f(t, u(t)), t \in(0,1), u(0)=u^{\prime \prime}(0)=0,\left({ }^{C} D_{0+}^{\sigma_{1}} u\right)(1)=\lambda\left(I_{0+}^{\sigma_{2}} u\right)(1)$, where $2<q<3,0<\sigma_{1} \leq 1$, $\sigma_{2}>0$, and $\lambda \neq \Gamma\left(2+\sigma_{2}\right) / \Gamma\left(2-\sigma_{1}\right)$. The main tools used are nonlinear alternative of Leray-Schauder type and Banach contraction principle.
\end{abstract}

\section{Introduction}

Fractional calculus has wide applications in many fields of science and engineering, for example, fluid flow, biosciences, rheology, electrical networks, chemical physics, control theory of dynamical systems, and optics and signal processing [1].

Recently, nonlinear fractional differential equations have been discussed under the following boundary conditions (BCs for short):

(1) Integer derivative BCs:

$$
\begin{aligned}
& u(0)=u(1)=0, \\
& u(0)+u^{\prime}(0)=0, u(1)+u^{\prime}(1)=0, \\
& u(0)=u^{\prime}(1)=u^{\prime \prime}(0)=0, \\
& u(0)=0, u^{\prime}(0)+u^{\prime \prime}(0)=0, u^{\prime}(1)+u^{\prime \prime}(1)=0, \\
& u(0)=u_{0}, u^{\prime}(0)=u_{0}^{*}, u^{\prime \prime}(T)=u_{T}, \\
& u(0)=u^{\prime}(1)=u^{\prime \prime}(0)=\cdots=u^{(n-1)}(0)=0 ;
\end{aligned}
$$

see papers [2-7], respectively.

(2) Integer derivative and integral BCs:

$$
\begin{aligned}
& \alpha u(0)-\beta u^{\prime}(0)=\int_{0}^{1} g(s) u(s) d s, \gamma u(1)+\delta u^{\prime}(1)= \\
& \int_{0}^{1} h(s) u(s) d s, \\
& u(0)=u^{\prime}(0)=u^{\prime \prime}(0)=0, u(1)=\lambda \int_{0}^{\eta} u(s) d s
\end{aligned}
$$

see papers $[8,9]$, respectively.
(3) Integer and fractional derivative BCs:

$$
\begin{aligned}
& u(0)=\left({ }^{C} D_{0+}^{\sigma_{1}} u\right)(1)=0, u^{\prime \prime}(0)=\left({ }^{C} D_{0+}^{\sigma_{2}} u\right)(1)= \\
& 0, \\
& u(0)=u^{\prime \prime}(0)=0, u^{\prime}(1)=\left({ }^{C} D_{0+}^{\sigma} u\right)(1), \\
& u(0)=u^{\prime}(0)=0, u^{\prime}(1)=\left({ }^{C} D_{0+}^{\sigma} u\right)(1), \\
& u(0)=0,\left(D_{0+}^{\beta} u\right)(1)=\sum_{i=1}^{m-2} \xi_{i}\left(D_{0+}^{\beta} u\right)\left(\eta_{i}\right), \\
& u(0)=0, u(1)+\left(D_{0+}^{\beta} u\right)(1)=k u(\xi)+l\left(D_{0+}^{\beta} u\right)(\eta), \\
& u(0)=0,\left(D_{0+}^{\beta} u\right)(1)=a\left(D_{0+}^{\beta} u\right)(\xi), \\
& u(0)=u^{\prime}(0)=\cdots=u^{(n-2)}(0)=0,\left(D_{0+}^{\alpha} u\right)(1)= \\
& 0 ;
\end{aligned}
$$

see papers [10-16], respectively.

(4) Integer derivative and fractional integral BCs:

$$
\begin{aligned}
& u(0)=\alpha I_{0+}^{p} u(\eta), \\
& u(0)=0, u^{\prime}(1)=I_{0+}^{\sigma} u(1) ;
\end{aligned}
$$

see papers $[17,18]$, respectively.

Besides, there are some other BCs involved in fractional differential equations, such as nonlinear BCs; refer to $[19,20]$.

Motivated greatly by the above-mentioned works, in this paper, we study the following boundary value problem (BVP for short) of nonlinear fractional differential equation with 
fractional integral BCs as well as integer and fractional derivative

$$
\begin{aligned}
\left({ }^{C} D_{0+}^{q} u\right)(t) & =f(t, u(t)), \quad t \in(0,1), \\
u(0) & =u^{\prime \prime}(0)=0, \\
\left({ }^{C} D_{0+}^{\sigma_{1}} u\right)(1) & =\lambda\left(I_{0+}^{\sigma_{2}} u\right)(1),
\end{aligned}
$$

where ${ }^{C} D_{0+}^{q}$ and ${ }^{C} D_{0+}^{\sigma_{1}}$ denote the standard Caputo fractional derivatives and $I_{0+}^{\sigma_{2}}$ denotes the standard Riemann-Liouville fractional integral. Throughout this paper, we always assume that $2<q<3,0<\sigma_{1} \leq 1, \sigma_{2}>0, \lambda \neq \Gamma\left(2+\sigma_{2}\right) / \Gamma\left(2-\sigma_{1}\right)$, and $f:[0,1] \times \mathbb{R} \rightarrow \mathbb{R}$ is continuous.

In order to prove our main results, the following wellknown fixed point theorems are needed.

Theorem 1 (nonlinear alternative of Leray-Schauder type [21]). Let $B$ be a Banach space with $E \subseteq B$ closed and convex. Assume $\Omega$ is a relatively open subset of $E$ with $\theta \in \Omega$ and $T: \bar{\Omega} \rightarrow E$ is a continuous and compact map. Then either

(a) Thas a fixed point in $\bar{\Omega}$ or

(b) there exists $u \in \partial \Omega$ and $\eta \in(0,1)$ such that $u=\eta T u$.

Theorem 2 (Banach contraction principle [22]). Let $(X, d)$ be a complete metric space and $T: X \rightarrow X$ be contractive. Then $T$ has a unique fixed point in $X$.

\section{Preliminaries}

In this section, we always assume that $\mathbb{N}=\{1,2,3, \ldots\}$, $\alpha, \beta>0$, and $[\alpha]$ denotes the integer part of $\alpha$. Now, for the convenience of the reader, we give the definitions of the Riemann-Liouville fractional integrals and fractional derivatives and the Caputo fractional derivatives on a finite interval of the real line, which may be found in [1].

Definition 3. The Riemann-Liouville fractional integrals $I_{0+}^{\alpha} u$ and $I_{1-}^{\alpha} u$ of order $\alpha$ on $[0,1]$ are defined by

$$
\begin{aligned}
& \left(I_{0+}^{\alpha} u\right)(t):=\frac{1}{\Gamma(\alpha)} \int_{0}^{t} \frac{u(s) d s}{(t-s)^{1-\alpha}}, \\
& \left(I_{1-}^{\alpha} u\right)(t):=\frac{1}{\Gamma(\alpha)} \int_{t}^{1} \frac{u(s) d s}{(s-t)^{1-\alpha}},
\end{aligned}
$$

respectively.

Definition 4. The Riemann-Liouville fractional derivatives $D_{0+}^{\alpha} u$ and $D_{1-}^{\alpha} u$ of order $\alpha$ on $[0,1]$ are defined by

$$
\begin{aligned}
\left(D_{0+}^{\alpha} u\right)(t) & :=\left(\frac{d}{d t}\right)^{n}\left(I_{0+}^{n-\alpha} u\right)(t) \\
& =\frac{1}{\Gamma(n-\alpha)}\left(\frac{d}{d t}\right)^{n} \int_{0}^{t} \frac{u(s) d s}{(t-s)^{\alpha-n+1}},
\end{aligned}
$$

$$
\begin{aligned}
\left(D_{1-}^{\alpha} u\right)(t) & :=\left(-\frac{d}{d t}\right)^{n}\left(I_{1-}^{n-\alpha} u\right)(t) \\
& =\frac{1}{\Gamma(n-\alpha)}\left(-\frac{d}{d t}\right)^{n} \int_{t}^{1} \frac{u(s) d s}{(s-t)^{\alpha-n+1}}
\end{aligned}
$$

respectively, where $n=[\alpha]+1$.

Definition 5. Let $D_{0+}^{\alpha}[u(s)](t) \equiv\left(D_{0+}^{\alpha} u\right)(t)$ and $D_{1-}^{\alpha}[u(s)](t)$ $\equiv\left(D_{1-}^{\alpha} u\right)(t)$ be the Riemann-Liouville fractional derivatives of order $\alpha$. Then the Caputo fractional derivatives ${ }^{C} D_{0+}^{\alpha} u$ and ${ }^{C} D_{1-}^{\alpha} u$ of order $\alpha$ on $[0,1]$ are defined by

$$
\begin{aligned}
& \left({ }^{C} D_{0+}^{\alpha} u\right)(t):=\left(D_{0+}^{\alpha}\left[u(s)-\sum_{k=0}^{n-1} \frac{u^{(k)}(0)}{k !} s^{k}\right]\right)(t), \\
& \left({ }^{C} D_{1-}^{\alpha} u\right)(t) \\
& :=\left(D_{1-}^{\alpha}\left[u(s)-\sum_{k=0}^{n-1} \frac{u^{(k)}(1)}{k !}(1-s)^{k}\right]\right)(t),
\end{aligned}
$$

respectively, where

$$
n= \begin{cases}{[\alpha]+1,} & \alpha \notin \mathbb{N}, \\ \alpha, & \alpha \in \mathbb{N} .\end{cases}
$$

Lemma 6 (see [23]). If $\alpha+\beta>1$, then the equation $\left(I_{0+}^{\alpha} I_{0+}^{\beta} u\right)(t)=\left(I_{0+}^{\alpha+\beta} u\right)(t), t \in[0,1]$, is satisfied for $u \in L_{1}[0$, $1]$.

Lemma 7 (see [23]). Let $\beta>\alpha$. Then the equation $\left({ }^{C} D_{0+}^{\alpha} I_{0+}^{\beta} u\right)(t)=\left(I_{0+}^{\beta-\alpha} u\right)(t), t \in[0,1]$, is satisfied for $u \in$ $C[0,1]$.

Lemma 8 (see [1]). Let $n$ be given by (5). Then the following relations hold:

(1) For $k \in\{0,1,2, \ldots, n-1\},{ }^{C} D_{0+}^{\alpha} t^{k}=0$.

(2) If $\beta>n$, then ${ }^{C} D_{0+}^{\alpha} t^{\beta-1}=(\Gamma(\beta) / \Gamma(\beta-\alpha)) t^{\beta-\alpha-1}$.

Lemma 9 (see [1]). Let $n$ be given by (5) and $u \in C^{n}[0,1]$. Then

$$
\begin{aligned}
\left(I_{0+}^{\alpha}{ }^{C} D_{0+}^{\alpha} u\right)(t)= & u(t)+c_{0}+c_{1} t+c_{2} t^{2}+\cdots \\
& +c_{n-1} t^{n-1},
\end{aligned}
$$

where $c_{i} \in \mathbb{R}, i=0,1, \ldots, n-1$.

For any $x \in L_{1}[0,1]$, we define

$$
\|x\|_{L_{1}}=\int_{0}^{1}|x(t)| d t .
$$

Lemma 10. Let $u \in L_{1}[0,1]$ be nonnegative. Then $\left(I_{0+}^{\alpha+1} u\right)(t)$ $\leq\left\|I_{0+}^{\alpha} u\right\|_{L_{1}}, t \in[0,1]$. 
Proof. For any $t \in[0,1]$, we have

$$
\begin{aligned}
\left(I_{0+}^{\alpha+1} u\right)(t) & =\frac{1}{\Gamma(\alpha+1)} \int_{0}^{t} \frac{u(s)}{(t-s)^{-\alpha}} d s \\
& =\frac{1}{\alpha \Gamma(\alpha)} \int_{0}^{t} u(s)(t-s)^{\alpha} d s \\
& =\frac{1}{\Gamma(\alpha)} \int_{0}^{t} u(s) \int_{s}^{t}(r-s)^{\alpha-1} d r d s \\
& =\frac{1}{\Gamma(\alpha)} \int_{0}^{t} \int_{0}^{r} \frac{u(s)}{(r-s)^{1-\alpha}} d s d r \\
& \leq \int_{0}^{1} \frac{1}{\Gamma(\alpha)} \int_{0}^{r} \frac{u(s)}{(r-s)^{1-\alpha}} d s d r \\
& =\int_{0}^{1}\left(I_{0+}^{\alpha} u\right)(r) d r=\left\|I_{0+}^{\alpha} u\right\|_{L_{1}} .
\end{aligned}
$$

\section{Main Results}

In the remainder of this paper, for any nonnegative function $g \in L_{1}[0,1]$, we denote

$$
\begin{aligned}
M_{g} & =\left\|I_{0+}^{q-1} g\right\|_{L_{1}} \\
& +\frac{\Gamma\left(2+\sigma_{2}\right) \Gamma\left(2-\sigma_{1}\right)}{\left|\lambda \Gamma\left(2-\sigma_{1}\right)-\Gamma\left(2+\sigma_{2}\right)\right|}\left[|\lambda|\left(I_{0+}^{q+\sigma_{2}} g\right)(1)\right. \\
& \left.+\left(I_{0+}^{q-\sigma_{1}} g\right)(1)\right]
\end{aligned}
$$

and for any $y \in C[0,1]$, we use the norm

$$
\|y\|_{\infty}=\max _{t \in[0,1]}|y(t)| \text {. }
$$

Lemma 11. Let $y \in C[0,1]$ be a given function. Then the $B V P$

$$
\begin{aligned}
\left({ }^{C} D_{0+}^{q} u\right)(t) & =y(t), \quad t \in(0,1), \\
u(0) & =u^{\prime \prime}(0)=0, \\
\left({ }^{C} D_{0+}^{\sigma_{1}} u\right)(1) & =\lambda\left(I_{0+}^{\sigma_{2}} u\right)(1)
\end{aligned}
$$

has a unique solution

$$
u(t)=\int_{0}^{1} G(t, s) y(s) d s, \quad t \in[0,1]
$$

where

$$
\begin{aligned}
G(t, s)= & -\frac{\Gamma\left(2+\sigma_{2}\right) \Gamma\left(2-\sigma_{1}\right)}{\lambda \Gamma\left(2-\sigma_{1}\right)-\Gamma\left(2+\sigma_{2}\right)} \\
& \cdot t\left[\frac{\lambda(1-s)^{q+\sigma_{2}-1}}{\Gamma\left(q+\sigma_{2}\right)}-\frac{(1-s)^{q-\sigma_{1}-1}}{\Gamma\left(q-\sigma_{1}\right)}\right] \\
& + \begin{cases}\frac{(t-s)^{q-1}}{\Gamma(q)}, & 0 \leq s \leq t \leq 1, \\
0, & 0 \leq t \leq s \leq 1 .\end{cases}
\end{aligned}
$$

Proof. It follows from the equation in (11) and Lemma 9 that

$$
u(t)=\left(I_{0+}^{q} y\right)(t)-c_{0}-c_{1} t-c_{2} t^{2}, \quad t \in[0,1] .
$$

So,

$$
\begin{aligned}
& u^{\prime}(t)=\left(I_{0+}^{q-1} y\right)(t)-c_{1}-2 c_{2} t, \quad t \in[0,1], \\
& u^{\prime \prime}(t)=\left(I_{0+}^{q-2} y\right)(t)-2 c_{2}, \quad t \in[0,1] .
\end{aligned}
$$

In view of (14), (16), and the BCs $u(0)=u^{\prime \prime}(0)=0$, we get

$$
c_{0}=c_{2}=0 \text {, }
$$

and so,

$$
u(t)=\left(I_{0+}^{q} y\right)(t)-c_{1} t, \quad t \in[0,1]
$$

Then, by using Lemmas 6,7 , and 8 , we may obtain

$$
\begin{aligned}
\left({ }^{C} D_{0+}^{\sigma_{1}} u\right)(t) & =\left(I_{0+}^{q-\sigma_{1}} y\right)(t)-c_{1} \frac{\Gamma(2)}{\Gamma\left(2-\sigma_{1}\right)} t^{1-\sigma_{1},} \\
t \in[0,1], & \\
\left(I_{0+}^{\sigma_{2}} u\right)(t) & =\left(I_{0+}^{q+\sigma_{2}} y\right)(t)-c_{1} \frac{\Gamma(2)}{\Gamma\left(2+\sigma_{2}\right)} t^{1+\sigma_{2}}, \\
t & \in[0,1],
\end{aligned}
$$

which together with the BC $\left({ }^{C} D_{0+}^{\sigma_{1}} u\right)(1)=\lambda\left(I_{0+}^{\sigma_{2}} u\right)(1)$ implies that

$$
\begin{aligned}
c_{1} & =\frac{\Gamma\left(2+\sigma_{2}\right) \Gamma\left(2-\sigma_{1}\right)}{\lambda \Gamma\left(2-\sigma_{1}\right)-\Gamma\left(2+\sigma_{2}\right)}\left[\lambda\left(I_{0+}^{q+\sigma_{2}} y\right)(1)\right. \\
& \left.-\left(I_{0+}^{q-\sigma_{1}} y\right)(1)\right] .
\end{aligned}
$$

Therefore, the BVP (11) has a unique solution

$$
\begin{aligned}
u(t) & =\left(I_{0+}^{q} y\right)(t) \\
- & \frac{\Gamma\left(2+\sigma_{2}\right) \Gamma\left(2-\sigma_{1}\right)}{\lambda \Gamma\left(2-\sigma_{1}\right)-\Gamma\left(2+\sigma_{2}\right)}\left[\lambda\left(I_{0+}^{q+\sigma_{2}} y\right)(1)\right. \\
- & \left.\left(I_{0+}^{q-\sigma_{1}} y\right)(1)\right] t=\int_{0}^{t}\left\{-\frac{\Gamma\left(2+\sigma_{2}\right) \Gamma\left(2-\sigma_{1}\right)}{\lambda \Gamma\left(2-\sigma_{1}\right)-\Gamma\left(2+\sigma_{2}\right)}\right. \\
\cdot & \left.t\left[\frac{\lambda(1-s)^{q+\sigma_{2}-1}}{\Gamma\left(q+\sigma_{2}\right)}-\frac{(1-s)^{q-\sigma_{1}-1}}{\Gamma\left(q-\sigma_{1}\right)}\right]+\frac{(t-s)^{q-1}}{\Gamma(q)}\right\} \\
\cdot & y(s) d s+\int_{t}^{1}\left\{-\frac{\Gamma\left(2+\sigma_{2}\right) \Gamma\left(2-\sigma_{1}\right)}{\lambda \Gamma\left(2-\sigma_{1}\right)-\Gamma\left(2+\sigma_{2}\right)}\right. \\
\cdot & \left.t\left[\frac{\lambda(1-s)^{q+\sigma_{2}-1}}{\Gamma\left(q+\sigma_{2}\right)}-\frac{(1-s)^{q-\sigma_{1}-1}}{\Gamma\left(q-\sigma_{1}\right)}\right]\right\} y(s) d s \\
= & \int_{0}^{1} G(t, s) y(s) d s, \quad t \in[0,1] .
\end{aligned}
$$


Lemma 12. Let $g \in L_{1}[0,1]$ be nonnegative. Then

$$
\int_{0}^{1}|G(t, s)| g(s) d s \leq M_{g}, \quad t \in[0,1]
$$

Proof. In view of Lemma 10, we have

$$
\begin{aligned}
& \int_{0}^{1}|G(t, s)| g(s) d s=\int_{0}^{t}|G(t, s)| g(s) d s \\
& +\int_{t}^{1}|G(t, s)| g(s) d s \\
& \leq \int_{0}^{t}\left\{\frac{\Gamma\left(2+\sigma_{2}\right) \Gamma\left(2-\sigma_{1}\right)}{\left|\lambda \Gamma\left(2-\sigma_{1}\right)-\Gamma\left(2+\sigma_{2}\right)\right|}\right. \\
& \cdot t\left[\frac{|\lambda|(1-s)^{q+\sigma_{2}-1}}{\Gamma\left(q+\sigma_{2}\right)}+\frac{(1-s)^{q-\sigma_{1}-1}}{\Gamma\left(q-\sigma_{1}\right)}\right] \\
& \left.+\frac{(t-s)^{q-1}}{\Gamma(q)}\right\} g(s) d s \\
& +\int_{t}^{1}\left\{\frac{\Gamma\left(2+\sigma_{2}\right) \Gamma\left(2-\sigma_{1}\right)}{\left|\lambda \Gamma\left(2-\sigma_{1}\right)-\Gamma\left(2+\sigma_{2}\right)\right|}\right. \\
& \left.\cdot t\left[\frac{|\lambda|(1-s)^{q+\sigma_{2}-1}}{\Gamma\left(q+\sigma_{2}\right)}+\frac{(1-s)^{q-\sigma_{1}-1}}{\Gamma\left(q-\sigma_{1}\right)}\right]\right\} g(s) d s \\
& =\frac{1}{\Gamma(q)} \int_{0}^{t} \frac{g(s)}{(t-s)^{1-q}} d s \\
& +\frac{\Gamma\left(2+\sigma_{2}\right) \Gamma\left(2-\sigma_{1}\right)}{\left|\lambda \Gamma\left(2-\sigma_{1}\right)-\Gamma\left(2+\sigma_{2}\right)\right|} t\left[\frac{|\lambda|}{\Gamma\left(q+\sigma_{2}\right)}\right. \\
& \cdot \int_{0}^{1} \frac{g(s)}{(1-s)^{1-q-\sigma_{2}}} d s+\frac{1}{\Gamma\left(q-\sigma_{1}\right)} \\
& \left.\cdot \int_{0}^{1} \frac{g(s)}{(1-s)^{1-q+\sigma_{1}}} d s\right]=\left(I_{0+}^{q} g\right)(t) \\
& +\frac{\Gamma\left(2+\sigma_{2}\right) \Gamma\left(2-\sigma_{1}\right)}{\left|\lambda \Gamma\left(2-\sigma_{1}\right)-\Gamma\left(2+\sigma_{2}\right)\right|} t\left[|\lambda|\left(I_{0+}^{q+\sigma_{2}} g\right)(1)\right. \\
& \left.+\left(I_{0+}^{q-\sigma_{1}} g\right)(1)\right] \leq\left\|I_{0+}^{q-1} g\right\|_{L_{1}} \\
& +\frac{\Gamma\left(2+\sigma_{2}\right) \Gamma\left(2-\sigma_{1}\right)}{\left|\lambda \Gamma\left(2-\sigma_{1}\right)-\Gamma\left(2+\sigma_{2}\right)\right|}\left[|\lambda|\left(I_{0+}^{q+\sigma_{2}} g\right)(1)\right. \\
& \left.+\left(I_{0+}^{q-\sigma_{1}} g\right)(1)\right]=M_{g}, \quad t \in[0,1] \text {. }
\end{aligned}
$$

Now, we define an operator $T: C[0,1] \rightarrow C[0,1]$ by

$$
(T u)(t)=\int_{0}^{1} G(t, s) f(s, u(s)) d s, \quad t \in[0,1] .
$$

Obviously, $u$ is a solution of the BVP (1) if and only if $u$ is a fixed point of $T$.
Theorem 13. Assume that $f(t, 0) \quad \not \equiv 0, t \in(0,1)$, and there exist nonnegative functions $g_{1}, g_{2} \in L_{1}[0,1]$, nonnegative increasing continuous function $\phi$ defined on $[0,+\infty)$, and $r>0$ such that

$$
|f(t, x)| \leq g_{1}(t)+g_{2}(t) \phi(|x|),
$$

$$
(t, x) \in[0,1] \times \mathbb{R},
$$

$$
M_{g_{1}}+\phi(r) M_{g_{2}}<r
$$

Then the BVP (1) has one nontrivial solution.

Proof. Let $\Omega=\left\{u \in C[0,1]:\|u\|_{\infty}<r\right\}$. Since $G(t, s)$ and $f(t, x)$ are continuous on $[0,1] \times[0,1]$ and $[0,1] \times \mathbb{R}$, respectively, we may denote

$$
\begin{aligned}
L & =\max _{(t, s) \in[0,1] \times[0,1]}|G(t, s)|, \\
H & =\max _{(t, x) \in[0,1] \times[-r, r]}|f(t, x)| .
\end{aligned}
$$

First, we prove that $T: \bar{\Omega} \rightarrow C[0,1]$ is continuous. Suppose that $u_{n}(n=1,2, \ldots), u_{0} \in \bar{\Omega}$, and $\left\|u_{n}-u_{0}\right\|_{\infty} \rightarrow 0$ $(n \rightarrow \infty)$. Then for any $n$ and $s \in[0,1]$, we have $\left|u_{n}(s)\right| \leq r$. This together with (27) and (28) implies that, for any $n$ and $t \in[0,1]$,

$$
\left|G(t, s) f\left(s, u_{n}(s)\right)\right| \leq L H, \quad s \in[0,1] .
$$

By applying Lebesgue dominated convergence theorem, we get

$$
\begin{aligned}
\lim _{n \rightarrow \infty}\left(T u_{n}\right)(t) & =\lim _{n \rightarrow \infty} \int_{0}^{1} G(t, s) f\left(s, u_{n}(s)\right) d s \\
& =\int_{0}^{1} G(t, s) f\left(s, u_{0}(s)\right) d s \\
& =\left(T u_{0}\right)(t), \quad t \in[0,1],
\end{aligned}
$$

which indicates that $T: \bar{\Omega} \rightarrow C[0,1]$ is continuous.

Next, we show that $T: \bar{\Omega} \rightarrow C[0,1]$ is compact. Assume that $K$ is a subset of $\bar{\Omega}$. Then for any $u \in K$, we have

$$
|u(s)| \leq r, \quad s \in[0,1] .
$$

In what follows, we will prove that $T(K)$ is relatively compact. On the one hand, for any $y \in T(K)$, there exists $u \in K$ such that $y=T u$, and so, it follows from (27), (28), and (31) that

$$
\begin{aligned}
|y(t)| & =|(T u)(t)|=\left|\int_{0}^{1} G(t, s) f(s, u(s)) d s\right| \\
& \leq \int_{0}^{1}|G(t, s)||f(s, u(s))| d s \leq L H,
\end{aligned}
$$

$$
t \in[0,1]
$$

which shows that $T(K)$ is uniformly bounded. On the other hand, for any $\varepsilon>0$, since $G(t, s)$ is uniformly continuous on 
$[0,1] \times[0,1]$, there exists $\delta>0$ such that, for any $t_{1}, t_{2} \in[0,1]$ with $\left|t_{1}-t_{2}\right|<\delta$,

$$
\left|G\left(t_{1}, s\right)-G\left(t_{2}, s\right)\right|<\frac{\varepsilon}{H}, \quad s \in[0,1] .
$$

For any $y \in T(K)$, there exists $u \in K$ such that $y=T u$, and so, for any $t_{1}, t_{2} \in[0,1]$ with $\left|t_{1}-t_{2}\right|<\delta$, it follows from (28), (31), and (33) that

$$
\begin{aligned}
& \left|y\left(t_{1}\right)-y\left(t_{2}\right)\right|=\left|(T u)\left(t_{1}\right)-(T u)\left(t_{2}\right)\right| \\
& \quad=\left|\int_{0}^{1}\left[G\left(t_{1}, s\right)-G\left(t_{2}, s\right)\right] f(s, u(s)) d s\right| \\
& \leq \int_{0}^{1}\left|G\left(t_{1}, s\right)-G\left(t_{2}, s\right)\right||f(s, u(s))| d s \\
& \quad \leq H \int_{0}^{1}\left|G\left(t_{1}, s\right)-G\left(t_{2}, s\right)\right| d s<\varepsilon,
\end{aligned}
$$

which indicates that $T(K)$ is equicontinuous. By ArzelaAscoli theorem, we know that $T(K)$ is relatively compact. Therefore, $T: \bar{\Omega} \rightarrow C[0,1]$ is compact.

Now, we will prove that (a) of Theorem 1 is fulfilled. Suppose on the contrary that (b) of Theorem 1 is satisfied; that is, there exists $u \in \partial \Omega$ and $\eta \in(0,1)$ such that $u=\eta T u$. Then, in view of (25), (26), and Lemma 12, we have

$$
\begin{aligned}
|u(t)|= & |\eta(T u)(t)| \leq|(T u)(t)| \\
= & \left|\int_{0}^{1} G(t, s) f(s, u(s)) d s\right| \\
\leq & \int_{0}^{1}|G(t, s)||f(s, u(s))| d s \\
\leq & \int_{0}^{1}|G(t, s)|\left[g_{1}(s)+g_{2}(s) \phi(|u(s)|)\right] d s \\
\leq & \int_{0}^{1}|G(t, s)| g_{1}(s) d s \\
& +\phi(r) \int_{0}^{1}|G(t, s)| g_{2}(s) d s \\
\leq & M_{g_{1}}+\phi(r) M_{g_{2}}<r, \quad t \in[0,1],
\end{aligned}
$$

which shows that

$$
\|u\|_{\infty}<r
$$

This contradicts the fact $u \in \partial \Omega$.

So, it follows from Theorem 1 that $T$ has a fixed point $u^{*}$, which is a desired solution of the BVP (1). At the same time, since $f(t, 0) \neq \equiv, t \in(0,1)$, we know that the zero function is not a solution of the BVP (1). Therefore, $u^{*}$ is a nontrivial solution of the BVP (1).
Theorem 14. Assume that there exists a nonnegative function $g_{3} \in L_{1}[0,1]$ such that

$$
\begin{gathered}
|f(t, x)-f(t, y)| \leq g_{3}(t)|x-y|, \\
\qquad t \in[0,1], x, y \in \mathbb{R}, \\
M_{g_{3}}<1 .
\end{gathered}
$$

Then the BVP (1) has a unique solution.

Proof. For any $u, v \in C[0,1]$, in view of (37) and Lemma 12, we have

$$
\begin{aligned}
& |(T u)(t)-(T v)(t)| \\
& \quad=\left|\int_{0}^{1} G(t, s)[f(s, u(s))-f(s, v(s))] d s\right| \\
& \quad \leq \int_{0}^{1}|G(t, s)||f(s, u(s))-f(s, v(s))| d s \\
& \quad \leq \int_{0}^{1}|G(t, s)| g_{3}(s)|u(s)-v(s)| d s \\
& \quad \leq\|u-v\|_{\infty} \int_{0}^{1}|G(t, s)| g_{3}(s) d s \leq M_{g_{3}}\|u-v\|_{\infty}, \\
& \quad t \in[0,1] .
\end{aligned}
$$

This indicates that

$$
\|T u-T v\|_{\infty} \leq M_{g_{3}}\|u-v\|_{\infty},
$$

which together with (38) implies that $T$ is contractive. So, it follows from Theorem 2 that $T$ has a unique fixed point, and so, the BVP (1) has a unique solution.

Example 15. We consider the BVP

$$
\begin{aligned}
\left({ }^{C} D_{0+}^{5 / 2} u\right)(t) & =t-\frac{t}{2} \sqrt{|u(t)|}, \quad t \in(0,1), \\
u(0) & =u^{\prime \prime}(0)=0, \\
\left({ }^{C} D_{0+}^{1 / 2} u\right)(1) & =\frac{1}{2}\left(I_{0+}^{3 / 2} u\right)(1) .
\end{aligned}
$$

Let $f(t, x)=t-(t / 2) \sqrt{|x|},(t, x) \in[0,1] \times \mathbb{R}$. Then $f$ : $[0,1] \times \mathbb{R} \rightarrow \mathbb{R}$ is continuous and $f(t, 0) \neq 0, t \in(0,1)$.

If we choose $g_{1}(t)=t, g_{2}(t)=t / 2, t \in[0,1]$, and $\phi(y)=$ $\sqrt{y}, y \in[0,+\infty)$, then it is easy to verify that (25) is satisfied.

Since $q=5 / 2, \sigma_{1}=1 / 2, \sigma_{2}=3 / 2$, and $\lambda=1 / 2$, a direct calculation shows that

$$
\begin{aligned}
\frac{\Gamma\left(2+\sigma_{2}\right)}{\Gamma\left(2-\sigma_{1}\right)} & =\frac{15}{4}, \\
M_{g_{1}} & =\frac{6656+4305 \pi}{43680 \sqrt{\pi}}, \\
M_{g_{2}} & =\frac{6656+4305 \pi}{87360 \sqrt{\pi}} .
\end{aligned}
$$

If we choose $r=1$, then (26) is fulfilled. 
Therefore, it follows from Theorem 13 that the BVP (41) has one nontrivial solution.

Example 16. We consider the BVP

$$
\begin{aligned}
& \left({ }^{C} D_{0+}^{5 / 2} u\right)(t) \\
& =\frac{t}{\pi}\left\{u(t) \arctan u(t)-\frac{1}{2} \ln \left[1+u^{2}(t)\right]\right\}, \\
& \quad t \in(0,1),
\end{aligned}
$$

$$
\begin{aligned}
& u(0)=u^{\prime \prime}(0)=0, \\
& \left({ }^{C} D_{0+}^{1 / 2} u\right)(1)=\frac{1}{2}\left(I_{0+}^{3 / 2} u\right)(1) .
\end{aligned}
$$

Let $f(t, x)=(t / \pi)\left[x \arctan x-(1 / 2) \ln \left(1+x^{2}\right)\right],(t, x) \epsilon$ $[0,1] \times \mathbb{R}$. Then $f:[0,1] \times \mathbb{R} \rightarrow \mathbb{R}$ is continuous.

If we choose $g_{3}(t)=t / 2, t \in[0,1]$, then we may assert that (37) is satisfied. In fact, for any $t \in[0,1]$, if $x=y$, then (37) is obvious. When $x \neq y$, we may suppose that $x<y$. In this case, by Lagrange mean value theorem, there exists $\xi \in(x, y)$ such that, for any $t \in[0,1]$,

$$
\begin{aligned}
& |f(t, x)-f(t, y)|=\frac{t}{\pi} \mid x \arctan x-\frac{1}{2} \ln \left(1+x^{2}\right) \\
& -y \arctan y+\frac{1}{2} \ln \left(1+y^{2}\right)\left|=\frac{t}{\pi}\right| \arctan \xi|| x \\
& \quad-y\left|\leq g_{3}(t)\right| x-y \mid ;
\end{aligned}
$$

that is, (37) is satisfied.

On the other hand, in view of $M_{g_{3}}=M_{g_{2}}=(6656+$ $4305 \pi) / 87360 \sqrt{\pi}$, we know that (38) is fulfilled.

Therefore, it follows from Theorem 14 that the BVP (43) has a unique solution.

\section{Competing Interests}

The authors declare that there is no conflict of interests regarding the publication of this paper.

\section{Acknowledgments}

This paper is supported by the National Natural Science Foundation of China (11661049).

\section{References}

[1] A. A. Kilbas, H. M. Srivastava, and J. J. Trujillo, Theory and Applications of Fractional Differential Equations, vol. 204 of North-Holland Mathematics Studies, Elsevier Science B.V., Amsterdam, The Netherlands, 2006.

[2] D. Jiang and C. Yuan, "The positive properties of the Green function for Dirichlet-type boundary value problems of nonlinear fractional differential equations and its application," Nonlinear Analysis: Theory, Methods \& Applications, vol. 72, no. 2, pp. 710-719, 2010.

[3] S. Zhang, "Positive solutions for boundary-value problems of nonlinear fractional differential equations," Electronic Journal of Differential Equations, vol. 2006, no. 36, pp. 1-12, 2006.
[4] Z. Bai and T. Qiu, "Existence of positive solution for singular fractional differential equation," Applied Mathematics and Computation, vol. 215, no. 7, pp. 2761-2767, 2009.

[5] J.-R. Yue, J.-P. Sun, and S. Zhang, "Existence of positive solution for BVP of nonlinear fractional differential equation," Discrete Dynamics in Nature and Society, vol. 2015, Article ID 736108, 6 pages, 2015.

[6] R. P. Agarwal, M. Benchohra, and S. Hamani, "Boundary value problems for fractional differential equations," Georgian Mathematical Journal, vol. 16, no. 3, pp. 401-411, 2009.

[7] K. Zhao and P. Gong, "Existence of positive solutions for a class of higher-order Caputo fractional differential equation," Qualitative Theory of Dynamical Systems, vol. 14, no. 1, pp. 157-171, 2015.

[8] W. Yang, "Positive solutions for nonlinear Caputo fractional differential equations with integral boundary conditions," Journal of Applied Mathematics and Computing, vol. 44, no. 1-2, pp. 39$59,2014$.

[9] X. Zhang, L. Wang, and Q. Sun, "Existence of positive solutions for a class of nonlinear fractional differential equations with integral boundary conditions and a parameter," Applied Mathematics and Computation, vol. 226, pp. 708-718, 2014.

[10] A. Guezane-Lakoud and R. Khaldi, "Existence results for a fractional boundary value problem with fractional Lidstone conditions," Journal of Applied Mathematics and Computing, vol. 49, no. 1-2, pp. 261-268, 2015.

[11] A. Guezane-Lakoud and S. Bensebaa, "Solvability of a fractional boundary value problem with fractional derivative condition," Arabian Journal of Mathematics, vol. 3, no. 1, pp. 39-48, 2014.

[12] R. Li, "Existence of solutions for nonlinear singular fractional differential equations with fractional derivative condition," Advances in Difference Equations, vol. 2014, article 292, 2014.

[13] Z.-W. Lv, "Positive solutions of m-point boundary value problems for fractional differential equations," Advances in Difference Equations, vol. 2011, Article ID 571804, 2011.

[14] Y. Ji, Y. Guo, J. Qiu, and L. Yang, "Existence of positive solutions for a boundary value problem of nonlinear fractional differential equations," Advances in Difference Equations, vol. 2015, article 13, 2015.

[15] C. F. Li, X. N. Luo, and Y. Zhou, "Existence of positive solutions of the boundary value problem for nonlinear fractional differential equations," Computers \& Mathematics with Applications, vol. 59, no. 3, pp. 1363-1375, 2010.

[16] J. Xu, Z. Wei, and W. Dong, "Uniqueness of positive solutions for a class of fractional boundary value problems," Applied Mathematics Letters, vol. 25, no. 3, pp. 590-593, 2012.

[17] S. K. Ntouyas, "Existence results for first order boundary value problems for fractional differential equations and inclusions with fractional integral boundary conditions," Journal of Fractional Calculus and Applications, vol. 3, no. 9, pp. 1-14, 2012.

[18] A. Guezane-Lakoud and R. Khaldi, "Solvability of a fractional boundary value problem with fractional integral condition," Nonlinear Analysis: Theory, Methods \& Applications, vol. 75, no. 4, pp. 2692-2700, 2012.

[19] W. Feng, S. Sun, X. Li, and M. Xu, "Positive solutions to fractional boundary value problems with nonlinear boundary conditions," Boundary Value Problems, 2014:225, 15 pages, 2014.

[20] W. Xie, J. Xiao, and Z. Luo, "Existence of extremal solutions for nonlinear fractional differential equation with nonlinear boundary conditions," Applied Mathematics Letters, vol. 41, pp. 46-51, 2015. 
[21] D. Guo and V. Lakshmikantham, Nonlinear Problems in Abstract Cones, Academic Press, San Diego, Calif, USA, 1988.

[22] A. Granas and J. Dugundji, Fixed Point Theory, Springer Monographs in Mathematics, Springer, New York, NY, USA, 2003.

[23] S. G. Samko, A. A. Kilbas, and O. I. Marichev, Fractional Integrals and Derivatives: Theory and Applications, Gordon and Breach Science, Yverdon, Switzerland, 1993. 


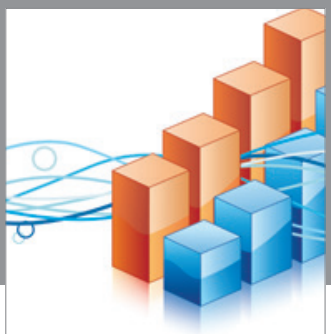

Advances in

Operations Research

vatem alat4

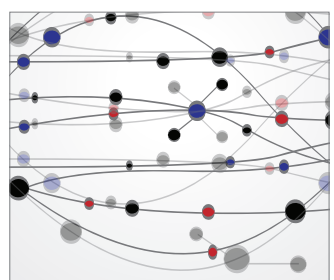

\section{The Scientific} World Journal
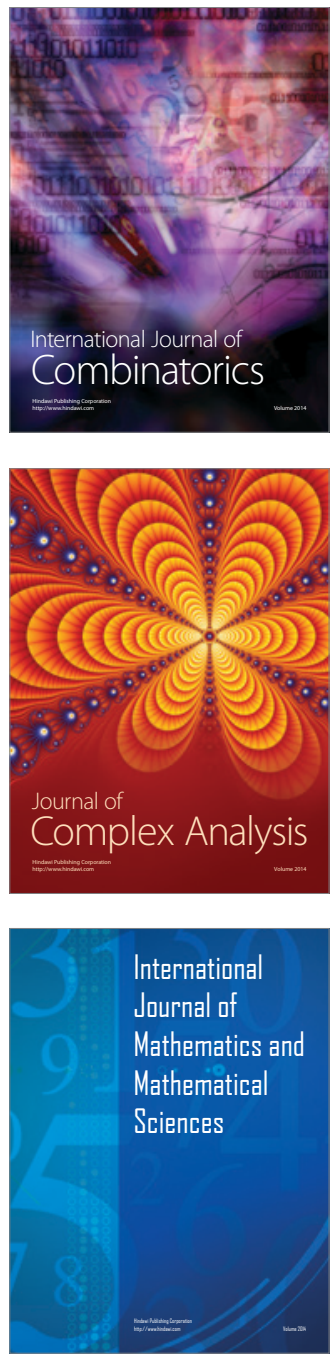
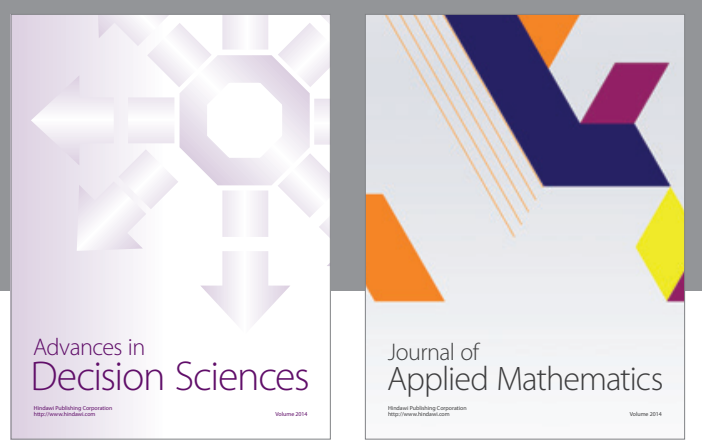

Algebra

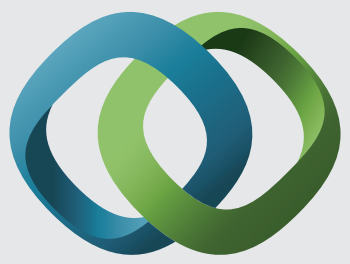

\section{Hindawi}

Submit your manuscripts at

https://www.hindawi.com
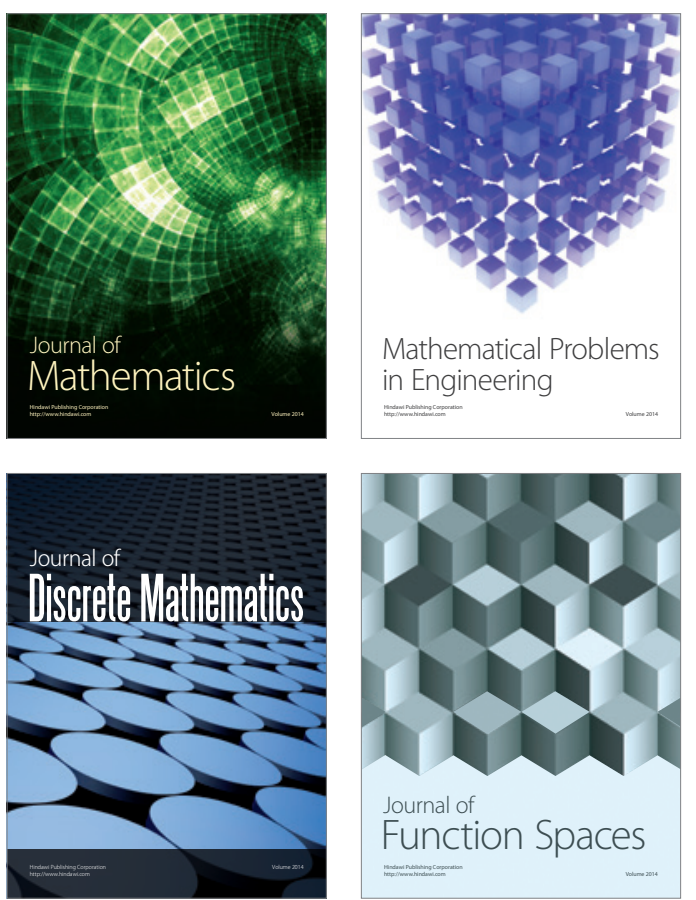

Mathematical Problems in Engineering
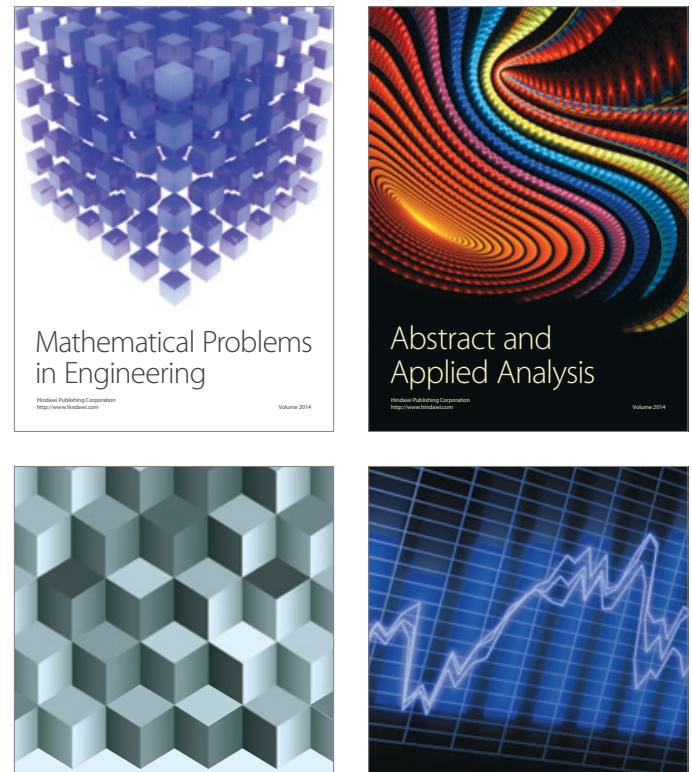

Journal of

Function Spaces

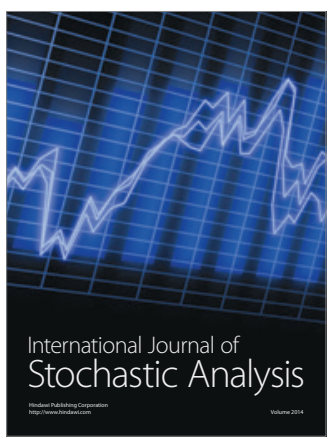

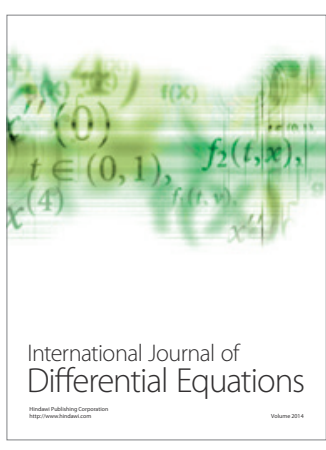
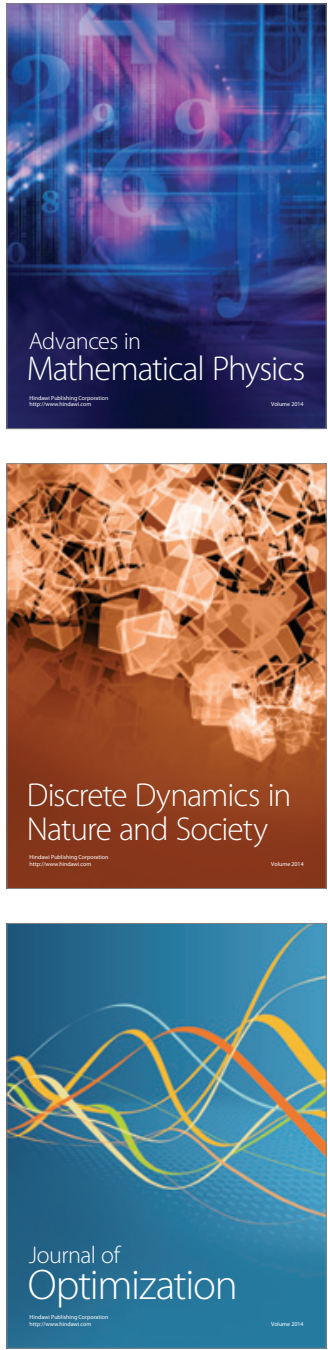